branches. Some axons projected to the buccal ganglion, in which 'follower' cells have previously been identified in neurophysiological studies, others crossed the midline, and several terminated in various muscles concerned with feeding behaviour in the mollusc.

In addition to light microscope autoradiography, Pentreath and Cottrell were also able to use electron microscopic autoradiography to investigate the fine structure of some of the labelled terminals. All of the injected label appeared to be confined to the injected neurones, and this method thus offers a relatively rapid and highly specific means of determining the various presynaptic terminals emanating from an identified single neurone.

It is clear that neuroanatomy has felt some of the impact of the molecular biology era, and that the battery of new techniques that have recently become available will stimulate an upsurge of activity in this area. Such a revival will come none too soon if one is to begin to understand the functional significance of the various chemically specific pathways of neurones that are now known to exist in the CNS.

L. L. IVERSEN

\title{
Clock and calendar in SI units
}

IN the SI system, one gives the time of day and date in kiloseconds, megaseconds and gigaseconds. The appropriate daytime clock has no minute hand and has a new face graduated $25-65 \mathrm{ks}$ (see figure); if the range $0-86.4 \mathrm{ks}$ was completed, the clock would also be suitable for night use. One's schedule might be: $25 \mathrm{ks}$, breakfast; $30 \mathrm{ks}$, start work; $45 \mathrm{ks}$, lunch; $60 \mathrm{ks}$, stop work; $65 \mathrm{ks}$, supper; $80 \mathrm{ks}$, retire.

On the calendar (see Table), one dates by the megasecond, stating a number under 100 with one decimal place. This increases daily except Sunday by $0.1 \mathrm{Ms}$. Thus, the eight days July 3-10, 1974, are 77.6, 77.7, 77.8, 77.9, 77.9+, 78.0, 78.1, 78.2 Ms. A + distinguishes Sunday. $0.1 \mathrm{Ms}$, however, must also be added on six Sundays out of 125 (since 1 week $0.6 \mathrm{Ms}=4.8 \mathrm{ks}$ ). The megasecond date then never differs from the actual time each day begins by more than $90.4 \mathrm{ks}$. After making a correction for this difference, one adds the time of day (see figure) to fix any instant absolutely.

This continuous calendar does not begin anew each year. Subtracting the megasecond at the new year from the current megasecond gives the time of year, useful in astronomy, weather, biology and farming. To place a date in history, one states the gigasecond to the nearest 0.1 ; for $1972-74$ this is 62.2 Gs.

The many advantages include elimination of timers graduated in diverse units, and of unsystematic derivatives such as revolution per minute and kilowatt hour. Moreover, $62278.2756 \mathrm{Ms}$ has fewer symbols and easier arithmetic than $11: 40$ a.m. July 10,1974 . Neither change in work schedules nor internationally agreed reform are needed; scientists and engineers can begin to use a SI clock and calendar today.

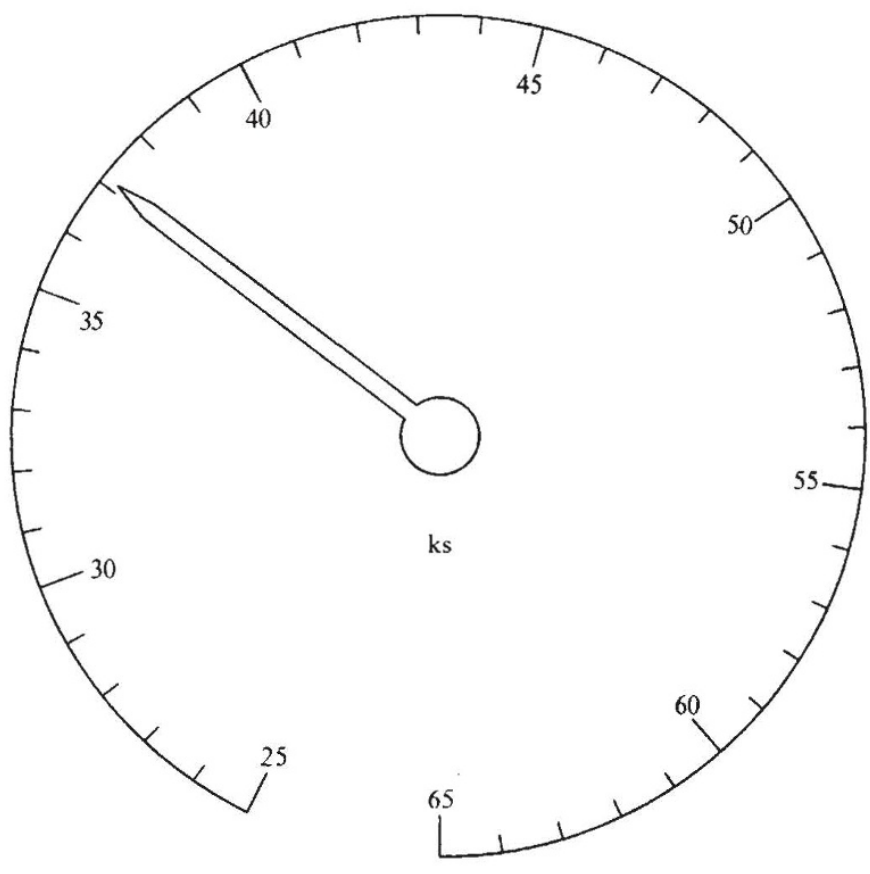

Charles E. ChaffeY

\begin{tabular}{|c|c|c|c|c|c|c|c|c|}
\hline \multicolumn{9}{|c|}{ Partial SI calendar } \\
\hline & Sunday & Monday & Tuesday & Wednesday & Thursday & Friday & Saturday & Date 1974 \\
\hline Ms & $77.3+$ & 77.4 & 77.5 & 77.6 & 77.7 & 77.8 & 77.9 & July 6 \\
\hline $\mathrm{ks}$ & 69.6 & 56.0 & 42.4 & 28.8 & 15.2 & 1.6 & -12.0 & \\
\hline Ms & $77.9+$ & 78.0 & 78.1 & 78.2 & 78.3 & 78.4 & 78.5 & July 13 \\
\hline ks & 74.4 & 60.8 & 47.2 & 33.6 & 20.0 & 6.4 & -7.2 & \\
\hline Ms & $78.5+$ & 78.6 & 78.7 & 78.8 & 78.9 & 79.0 & 79.1 & July 20 \\
\hline ks & 79.2 & 65.6 & 52.0 & 38.4 & 24.8 & 11.2 & -2.4 & \\
\hline Ms & $79.1+$ & 79.2 & 79.3 & 79.4 & 79.5 & 79.6 & 79.7 & July 27 \\
\hline ks & 84.0 & 70.4 & 56.8 & 43.2 & 29.6 & 16.0 & 2.4 & \\
\hline Ms & $79.7+$ & 79.8 & 79.9 & 80.0 & 80.1 & 80.2 & 80.3 & August 3 \\
\hline ks & 88.8 & 75.2 & 61.6 & 48.0 & 34.4 & 20.8 & 7.2 & \\
\hline Ms & $80.4+$ & 80.5 & 80.6 & 80.7 & 80.8 & 80.9 & 81.0 & August 10 \\
\hline ks & -6.4 & -20.0 & -33.6 & -47.2 & -60.8 & -74.4 & -88.0 & \\
\hline
\end{tabular}

Add 62.2 Gs. New Year was $61.8 \mathrm{Ms}$. The beginning of each day is the sum of the large figure (in Ms) and the small figure (in ks). 